\title{
KOREKSI NILAI KONSTANTA "K” DALAM PERHITUNGAN USIA PAKAI KOMPONEN UNDERCARRIAGE KOMATSU D375A-5
}

\author{
Syaeful Akbar, Randis Baharuddin \\ Jurusan Teknik Mesin, Program Studi Teknik Mesin Alat Berat \\ Politeknik Negeri balikpapan \\ Email:Syaeful.akbar@poltekba.ac.id,Randis@poltekba.ac.id
}

\begin{abstract}
ABSTRAK
Performa unjuk kerja Bulldozer Komatsu D375A-5 sangat bergantung pada komponen undercarriage. Jika komponen undercarriage mengalami keausan melebihi batas yang diijinkan, maka performa dan produktifitas kerjanya akan menurun. Oleh karena itu tindakan melakukan monitoring dan pengukuran tingkat keausan komponen undercarriage menjadi suatu hal yang sangat penting untuk memprediksi sampai seberapa lama lagi komponen tersebut masih bisa dipakai. Persamaan yang digunakan untuk memprediksi usia pakai komponen undercarriage adalah $W r=a . x^{k}$. Nilai konstanta " $k$ " untuk setiap komponen berbeda. Komatsu telah menetapkan nilai " $k$ " untuk link-pitch $=1,3$; linkheight = 2,0; Bushing O/D =2,0; Grouser Height = 1,0; Carrier Roller =1,3; Idler = 1,8; Sprocket =1,0; dan Track Roller = 1,5. Penelitian ini dimaksudkan untuk menguji apakah prediksi usia pakai komponen undercarriage dengan nilai konstanta " $k$ " sebagaimana tersebut diatas sesuai dengan fakta dilapangan?. Metoda penelitian yang digunakan adalah dengan cara membandingkan hasil perdiksi perhitungan menggunakan persamaan dan nilai konstanta " $k$ " yang sudah ditetapkan oleh Komatsu, dengan hasil perhitungan usia pakai secara actual dilapangan, selanjutnya kedua hasil perhitungan tersebut dilakukan uji paired " $t$ " test. Adapun sampel data yang digunakan adalah data hasil pengukuran P2U Dozer Komatsu D375A-5 yang beroperasi di area tambang batubara site Batukajang antara tahun 2013 s/d tahun 2014. Dari hasil pengujian ditemukan bahwa nilai " $k$ " untuk komponen Link Pitch, Link height dan Sprocket tidak sesuai dengan actual di lapangan dan terkoreksi menjadi Link Pitch = 1,6; Link height $=1,7$ dan Sprocket = 2,5. Sedangkan nilai konstanta " $k$ " untuk komponen yang lainnya sesuai dengan hasil perhitungan secara actual di lapangan.
\end{abstract}

Kata kunci: nilai “ $k$ ”, prediksi, usia pakai, komponen, undercarriage

\begin{abstract}
The performance of Komatsu D375A-5 Bulldozer is very dependent on the undercarriage component. If the undercarriage component wears over the allowable limit, then its performance and productivity will decrease. Therefore the act of monitoring and measuring the component wear rate of an undercarriage is very important to predict how long the component can still be used. The equation used to predict the service life of the undercarriage component was $W r=a . x k$. The constant value " $k$ " for each component was different. Komatsu had set the " $k$ " value for link-pitch $=1.3$; link-height $=2.0$; Bushing $O / D=2.0$; Grouser Height =1.0; Carrier Roller =1.3; Idler =1.8; Sprocket
\end{abstract}


=1.0; and Track Roller = 1.5. This study aimed to test whether the prediction of service life of undercarriage component with a constant value " $k$ " as above was in accordance with the facts in the field. The research method used was by comparing the results of the calculation prediction using the equation and the constant value " $k$ " that had been determined by Komatsu, with the actual calculation of the service life in the field, then the two results of the calculation were carried out by paired " $t$ " test. The data sample used were the measurement data of P2U Dozer Komatsu D375A-5 which operated in the coal mine area of the Batu kajang site between 2013 and 2014. From the test results it was found that the value " $k$ " for the Link Pitch component, Link height and Sprocket did not match the actual in the field and corrected to Link Pitch = 1.6; Link height $=$ 1.7 and Sprocket $=2.5$. While the constant value " $k$ " for the other components were in accordance with the actual calculation results in the field.

Keywords: "k"value, prediction, service life, component, undercarriage

\section{PENDAHULUAN}

Bulldozer Komatsu D375A-5 merupakan Crawler Dozer yang memiliki kapasitas blade $22 \mathrm{~m}^{3}$ dengan tenaga mesin sebesar $525 \mathrm{HP}$ pada $1800 \mathrm{rpm}$ [1]. Unit ini banyak digunakan di area pertambangan untuk pekerjaan road construction, land clearing dan meratakan disposal soil.

Performa unjuk kerja Bulldozer D375A-5 sangat bergantung pada komponen undercarriage [2]. Jika komponen undercarriage mengalami keausan melebihi batas yang diijinkan, maka performa dan produktifitas kerjanya akan menurun [6]. Oleh karena itu tindakan melakukan monitoring dan pengukuran tingkat keausan komponen undercarriage menjadi suatu hal yang sangat penting untuk memprediksi sampai seberapa lama lagi komponen tersebut masih bisa dipakai [3].

Memprediksi usia pakai komponen undercarriage secara tepat menjadi sangat penting, agar efisiensi biaya maintenance dan efisiensi produksi dapat tercapai [7].

Cara menghitung usia pakai komponen undercarriage yang biasa digunakan adalah dengan menghitung prosentase laju tingkat keausan komponen menggunakan persamaan sebagai berikut [3]:

(Pers. 1)

$$
\begin{aligned}
& \mathrm{Wr}=\frac{\mathrm{Sv}-\mathrm{Mw}}{\mathrm{Sv}-\mathrm{Wl}} \times 100 \% \\
& W r=\text { Worn }(\text { wear rate }) \\
& S v=\text { Standard value } \\
& M w=\text { Measured } \text { wear rate } \\
& W l=\text { Wear limit }
\end{aligned}
$$

Selanjutnya untuk memprediksi usia pakai komponen digunakan persamaan sebagai berikut [3]:

(Pers. 2)

$$
\begin{aligned}
& W r=a \cdot X^{k} \\
& W r=\text { Wear rate } \\
& a=\text { Constanta } \\
& X=\text { Operating hours } \\
& k=\text { Factor Component }
\end{aligned}
$$


Nilai konstanta " $k$ " pada masing-masing komponen berbeda. Komatsu telah menetapkan nilai konstanta " $k$ " untuk masing-masing komponen undercarriage dapat dilihat pada tabel 1 [3].

Tabel 1: Nilai konstanta "k"

\begin{tabular}{lc}
\hline \multicolumn{1}{c}{ Nama komponen } & Nilai "k" \\
\hline Link Pitch & 1,3 \\
Link Height & 2,0 \\
Bushing O/D & 2,0 \\
Grouser Height & 1,0 \\
Carrier Roller & 1,3 \\
Idler & 1,8 \\
Sprocket & 1,0 \\
Track Roller & 1,5 \\
\hline
\end{tabular}

Penelitian ini dimaksudkan untuk membuktikan apakah hasil perhitungan prediksi usia pakai komponen undercarriage Komatsu D375A-5 dengan nilai konstanta " $k$ " tersebut diatas, sesuai dengan hasil perhitungan secara actual di lapangan.

Adapun perhitungan usia pakai secara actual dapat dihitung dengan cara membagi tingkat keausan yang diijinkan dengan tingkat keausan perjam. tingkat keausan yang diijinkan adalah ukuran standar dikurangi dengan batas limit yang diijinkan. Adapun tingkat keausan perjam adalah tingkat keausan dalam kurun waktu tertentu dibagi dengan waktu (jam) pemakaian.

\section{METODOLOGI PENELITIAN}

Hasil perhitungan prediksi usia pakai setiap komponen undercarriage dengan menggunakan nilai konstata "k" sesuai dengan tabel diatas, selanjutnya dibandingkan dengan hasil perhitungan secara actual dengan menggunakan uji paired " $\mathrm{t}$ " test dua arah dengan tingkat kepercayaan $95 \%$. Jika nilai signifikansi t test $>0,05$, maka hasil prediksi usia pakai komponen sama dengan actual. Sebaliknya jika nilai signifikansi " $t$ " test $<0,05$, maka nilai konstanta " $k$ " perlu dikoreksi.

Hipotesa yang digunakan dalam penelitian ini adalah :

$\mathrm{H}_{\mathrm{o}}$ : Hasil prediksi perhitungan usia pakai komponen undercarriage sama dengan actual.

$\mathrm{H}_{\mathrm{a}}$ : Hasil prediksi perhitungan usia pakai komponen undercarriage tidak sama dengan actual.

\section{Metode Pengumpulan Data}

Penelitian ini menggunakan data sekunder berupa hasil pengukuran P2U bulldozer komatsu D375A-5 yang dioperasikan di area pertambangan Site Batukajang untuk aplikasi mendorong tanah antara tahun 2013 sampai dengan tahun 2014. Jumlah sampel yang digunakan adalah 11 unit bulldozer Komatsu D375A-5 yang diukur setiap beroperasi \pm 400 jam.

\section{Metode Pengolahan Data}

Data mentah hasil pengukuran P2U sesuai dengan measuring form [5] yang dilakukan pada setiap \pm 400 jam operasi, selanjutnya diolah untuk mendapatkan prediksi nilai usia pakai komponen menggunakan persamaan 2. Selanjutnya menghitung usia pakai komponen undercarriage secara actual dengan menggunakan persamaan. Hasil perhitungan dari kedua metode tersebut selanjutnya diuji menggunakan uji " $\mathrm{t}$ " test dua arah dengan menggunakan persamaan $5[3]$. 


$$
t=\frac{\overline{\mathrm{X}_{1}}-\mathrm{X}_{2}^{-}}{\sqrt{\frac{s_{1}^{2}}{n_{1}}+\frac{s_{2}^{2}}{n_{2}}-2 r\left(\frac{s_{1}}{\sqrt{n_{1}}}\right)\left(\frac{s_{2}}{\sqrt{n_{2}}}\right)}}
$$

$\mathrm{X}_{1}=$ rata-rata sampel -1

$\mathrm{X}_{2}=$ rata-rata sampel -2

$\mathrm{S}_{1}^{2}=$ varian sampel -1

$\mathrm{S}_{2}^{2}=$ varian sampel -2

$\mathrm{S}_{1}=$ simpangan baku sampel -1

$\mathrm{S}_{2}=$ simpangan baku sampel -2

$\mathrm{n}_{1}=$ Jumlah sampel -1

$\mathrm{n}_{2}=$ Jumlah sampel -2

Apabila hasil uji nilai "t" hitung berada didalam area keberterimaan sesuai " $t$ " tabel, maka $\mathrm{H}_{\mathrm{o}}$ diterima, sebaliknya jika nilai " $\mathrm{t}$ " hitung berada diluar keberterimaan sesuai " $\mathrm{t}$ " tabel, maka $\mathrm{H}_{\mathrm{o}}$ ditolak dan $\mathrm{H}_{\mathrm{a}}$ diterima. Nilai " $\mathrm{t}$ ” tabel yang digunankan pada angka kepercayaan 95\%. Sedangkan jika menggunakan SPSS, maka $\mathrm{H}_{\mathrm{o}}$ diterima jika nilai Signifikan $>0.05$, sebaliknya $\mathrm{H}_{\mathrm{o}}$ ditolak jika nilai Signifikan $<0.05$.

Adapun flow chart metode pengolahan data dapat dilihat pada gambar 1 .

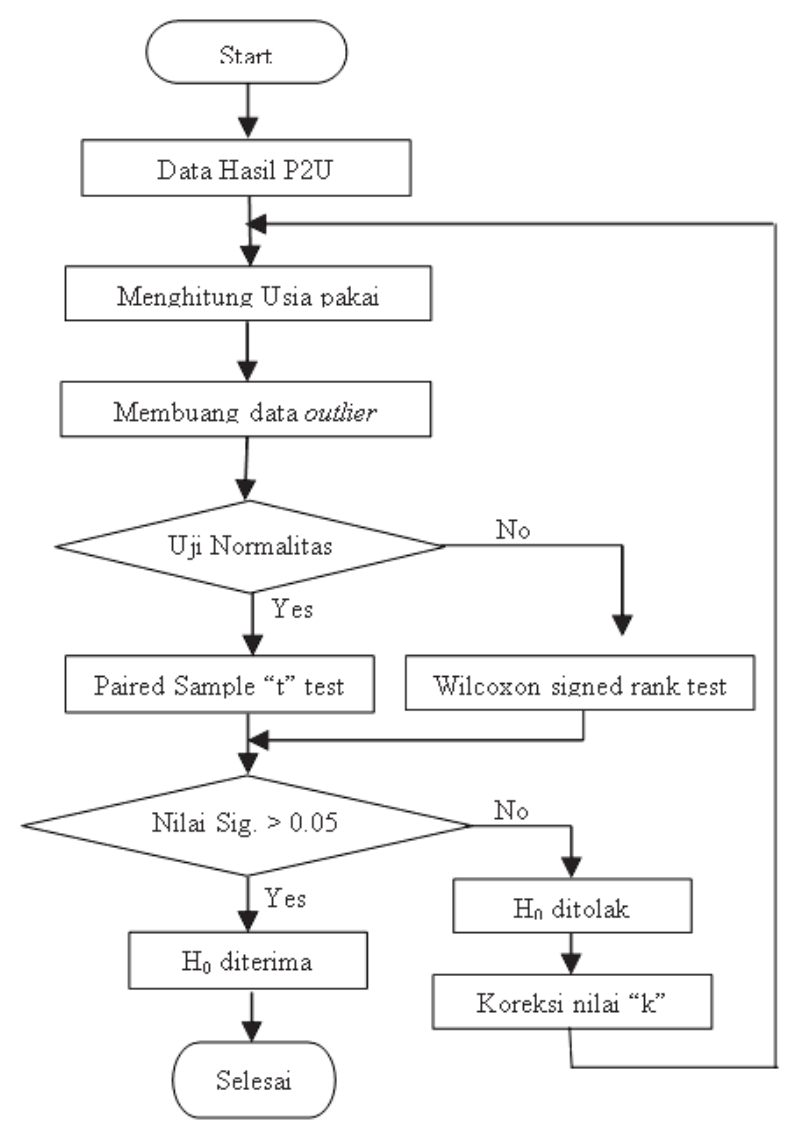

Gambar 1 : Flow chart pengolahan data 


\section{HASIL DAN PEMBAHASAN}

Pengukuran komponen undercarriage meliputi : Link pitch, Link height, Bushing $O / D$, Gourser height, Carrier roller, Idler, Sprocket, dan Track roller. Hasil uji "t" test dari hasil prediksi perhitungan usia pakai komponen undercarriage dan hasil perhitungan secara actual dapat dilihat pada tabel 2.

Tabel 2 : Hasil uji “ $t$ ”" test

\begin{tabular}{|l|r|r|r|r|r|r|r|r|}
\hline Uraian & Track-link & Link-height & Bushing-OD & Groser-height & Carrier-roller & Idler & Sprocket & Track-roller \\
\hline $\mathrm{k}$ & 1.3 & 2.0 & 2.0 & 1.0 & 1.3 & 1.8 & 1.0 & 1.5 \\
\hline $\mathrm{n}$ & 136 & 146 & 152 & 144 & 225 & 150 & 114 & 969 \\
\hline $\mathrm{df}$ & 135 & 145 & 151 & 143 & 224 & 149 & 113 & 968 \\
\hline $\mathrm{t}$ tans & 13.631 & 3.854 & -1.446 & 0.276 & 0.864 & -1.101 & 9.972 & 1.815 \\
\hline tas* & 1.978 & 1.976 & 1.976 & 1.977 & 1.971 & 1.976 & 1.981 & 1.962 \\
\hline $\mathrm{t}$ Sig & 0.000 & 0.000 & 0.150 & 0.783 & 0.389 & 0.273 & 0.000 & 0.212 \\
\hline Conclusion & Ho ditolak & Ho ditolak & Ho diterima & Ho diterima & Ho diterima & Ho dinerima & Ho ditolak & Ho diterima \\
\hline
\end{tabular}

Dari hasil perhitungan uji “t”" test, sebagaimana terlihat dalam tabel 1, menunjukan bahwa prediksi usia pakai komponen undercarriage dengan nilai faktor " $\mathrm{k}$ " sebagaimana ditetapkan oleh Komatsu menunjukan bahwa untuk komponen : Bushing O/D, Grouser height, Carrier roller, Idler, dan Track roller adalah sama dengan actual. Sedangkan untuk Track link, Link height, dan sprocket tidak sesuai dengan actual. Berdasarkan hal tersebut, maka dilakukan uji coba dengan merubah nilai faktor " $k$ " dengan metode try and error sampai diperoleh nilai faktor " $k$ " yang dapat menghasilkan nilai prediksi sama dengan usia pakai komponen secara actual.

Setelah dilakukan uji coba merubah nilai "k" ditemukan nilai koreksi faktor "k" untuk komponen Track link terkoreksi dari 1.3 menjadi 1.6, Link height dari 2.0 menjadi 1.7, dan Sprocket dari 1.0 menjadi 2.5 .

Tabel 3 : Nilai Koreksi kontanta "k"

\begin{tabular}{|l|c|c|c|}
\hline $\begin{array}{l}\text { Nama } \\
\text { Komponen }\end{array}$ & Nilai "k" & $\begin{array}{l}\text { Nilai ' } k " \\
\text { Koreksi }\end{array}$ & Keterangan \\
\hline Link Pitch & 1,3 & 1,6 & Koreksi \\
\hline Link Height & 2,0 & 1,7 & Koreksi \\
\hline Bushing O D & 2,0 & 2,0 & Sesuai \\
\hline Grouser Height & 1,0 & 1,0 & Sesuai \\
\hline Carrier Roller & 1,3 & 1,3 & Sesuai \\
\hline Idler & 1,8 & 1,8 & Sesuai \\
\hline Sprocket & 1,0 & 2.5 & Koreksi \\
\hline Track Roller & 1,5 & 1,5 & Sesuai \\
\hline
\end{tabular}

Adapun hasil uji " $t$ " test setelah dilakukan perubahan nilai " $\mathrm{k}$ " dapat dilihat pada tabel 4 di bawah. 
Tabel 4 : Hasil uji " $t$ " test setelah koreksi nilai " $k$ "

\begin{tabular}{|c|c|c|c|c|c|c|c|c|}
\hline Jraian & Trackilink & Link-heipht & Bushing-00 & Grouser height & Carrier-foller & idler & Sprocket & Track-roller \\
\hline${ }^{\prime \prime}$ & 1.6 & 1.7 & 2.0 & 1.0 & 1.3 & 1.8 & 2.5 & 1.5 \\
\hline$N$ & 136 & 146 & 152 & 144 & 225 & 150 & 114 & 969 \\
\hline of & 135 & 145 & 151 & 143 & 224 & 149 & 113 & 968 \\
\hline buces & $-135 s$ & -1.597 & -1.446 & 0.276 & 0.864 & -1.101 & 1.542 & $1.81 \mathrm{~s}$ \\
\hline Sene: & 1978 & 1.976 & 1.976 & 1977 & 1971 & 1976 & 1.981 & 1.962 \\
\hline tsig & 0.065 & 0.120 & 0.150 & 0.783 & 0.359 & 0.273 & 0.126 & 0.212 \\
\hline Concluzion & $\mathrm{H}_{9}$ dititerims & My diterims & Hy diferims & $\mathrm{H}_{2}$ diterims & $\mathrm{H}_{2}$ eliterims & $\mathrm{H}_{2}$ diterims & $\mathrm{H}_{3}$ elinerims & Moditerimg \\
\hline
\end{tabular}

\section{KESIMPULAN}

Setelah dilakukan uji statistic parametric antara hasil perhitungan prediksi usia pakai komponen undercarriage dengan nilai faktor " $k$ " sebagai mana ditetapkan oleh Komatsu tidak semuanya sesuai dengan usia pakai secara actual di lapangan. Hasil uji "t" test menunjukan bahwa nilai signifikansi untuk komponen Bushing O/D, Grouser height, Carrier roller, Idler, dan Track roller lebih besar dari 0,005 yang artinya tidak ada perbedaan antara perhitungan prediksi usia pakai komponen undercarriage dengan usia pakai secara actual di lapangan.

Hal ini berarti bahwa nilai "k" untuk component tersebut diatas dapat diterima. Sedangkan hasil uji "t" test untuk komponen Track link, Link height, dan Sprocket menunjukan angka signifikansi yang kurang dari 0,005 artinya bahwa hasil prediksi usia pakai komponen undercarriage dengan nilai faktorn " $k$ " sebagai mana yang telah ditetapkan oleh Komatsu tidak sesuai dengan usia pakai secara actual dilapangan. Dengan demikian dapat disimpulkan bahwa nilai faktor " $k$ " yang sudah ditetapkan oleh Komatsu untuk memprediksi usia pakai komponen Track link, Link height, dan Sprocket tidak dapat diterima. Oleh karena itu, nilai faktor "k" untuk komponen tersebut perlu dikoreksi.

Setelah dilakukan koreksi dengan merubah nilai faktor "k" untuk komponen Track link, Link height, dan Sprocket serta dilakukan uji "t" test ulang, ditemukan nilai koreksi faktor "k" untuk komponen Link Pitch terkoreksi dari 1,3 menjadi 1,6; Link height dari 2,0 menjadi 1,7 dan Sprocket dari 1,0 menjadi 2,5.

\section{KESIMPULAN}

Dengan ditemukannya nilai koreksi faktor "k" untuk perhitungan prediksi usia pakai komponen Track link, Link height, dan Sprocket maka disarankan untuk selanjutnya dalam menghitung prediksi usia pakai komponen Track link, Link height, dan Sprocket tidak lagi menggunkan nilai faktor " $k$ " yang sudah ditetapkan oleh Komatsu, tetapi menggunakan nilai konatanta " $k$ " terkoreksi tersebut diatas.

Nilai koreksi "k" tersebut diatas baru terbukti untuk perhitungan prediksi usia pakai komponen undercarriage Bulldozer Komatsu D375A-5 untuk aplikasi Dozing of disposal soil. Sedangkan untuk aplikasi yang lain perlu dulakukan penelitian lebih lanjut.

\section{DAFTAR PUSTAKA}

[1] Komatsu, (2002), Komatsu Europe International NV Mechelsesteenweg 586, Belgium.

[2] J. Hidayah, (2011), "Peningkatan Perawatan Komponen Undercarriage Alat Berat"

[3] Mechanic Development PT. Pamapesada Nusantara (2003) "Sistem Final Drive \& Undercarriage"

[4] D. M. Levine, D. F. Stephan, T. C. Krehbiel, dan M. L. Berenson, "The Normal Distribution," pada Statistics for Managers Using Microsoft Excel, Edisi Kelima, Upper Saddle River, New Jersey: Prentice-Hall, 2008, hal. 201. 
[5] Caterpillar,. (2011) Cat Undercarriage Management System, Cat, Caterpillar USA.

[6] Sugiyono, (2007) Statistika untuk Penelitian, CV Alfabeta, Bandung.

[7] West-Track, Undercarriage Handbook, Westport, New Zealand. 